\title{
O Conhecimento Científico como Instrumento Central na Tomada de Decisão na Administração Pública - Sobre a Pandemia de COVID-19 no Brasil \\ Scientific Knowledge as a Central Instrument in Public Administration Making Decision - About the COVID-19 Pandemic in Brazil
}

\author{
Tarcísio Marciano da Rocha Filho'
}

\begin{abstract}
RESUMO
Discutimos porque, ao desconsiderar as informações e análises geradas pela comunidade científica nacional e internacional, gestores públicos e mesmo privados tomam decisões equivocadas e nefastas para o interesse geral e privado, sobretudo durante uma crise transformadora com a pandemia de COVID-19. Apontamos qual deveriam ser os pontos centrais para um relacionamento correto entre a comunidade científica e os gestores públicos.
\end{abstract}

Palavras chave: Ciência e tomada de decisão; Gestão pública; Pandemia de COVID19.

\begin{abstract}
We discuss that by not taking into account information and analysis provided by the scientific community, public and private sector decision makers chose to take seriously mistaken and nefarious decisions, for both the general public and private sectors. WE point a few key factors that should guide a more productive relationship between the scientific community and public managers,
\end{abstract}

Keywords: Science and decision making; Public administration; COVID-19 Pandemic.

A epidemia mundial do vírus SARS-CoV-2, que causa a doença denominada COVID-19, tem trazido a público fragilidades da máquina estatal brasileira, desde as responsabilidades e limites da União para com as demais unidades da federação, estados e municípios, bem como a condução do Governo Federal na planificação de políticas de antecipação, mitigação e orientação do país neste momento. A possibilidade de pandemia já estava colocada claramente, desde meados de janeiro, e houve tempo hábil para uma planificação e preparo mínimos antes da entrada e da livre circulação do SARS-CoV-2 no Brasil, que incluiriam, entre outras medidas, compra de respiradores, de insumos para testes e o preparo da

\footnotetext{
1 Coordenador do NAEED (Núcleo de Altos Estudos Estratégicos para o Desenvolvimento); Vice-Diretor do CIFMC (Centro Internacional de Física da Matéria Condensada); Professor do Instituto de Física da Universidade de Brasília. E-mail: tmrf1962@gmail.com
}

Artigo Convidado para compor este Fórum Especial em Democracia, Políticas Públicas e COVID-19. Agradecemos ao autor a participação neste debate tão urgente. 
infraestrutura laboratorial e hospitalar.

O fato é que as fragilidades e disputas políticas afloraram neste momento com maior vigor, bem como a descoordenação e lentidão da máquina estatal em apresentar alternativas para o enfrentamento da pandemia em todo território nacional, que criam, por sua vez, ainda mais dificuldades para enfrentar uma crise sanitária de imensas implicações em todas as esferas da sociedade brasileira, e mundial.

O fato é que as fragilidades e disputas políticas afloraram neste momento com maior vigor, bem como a descoordenação e lentidão da máquina estatal em apresentar alternativas para o enfrentamento da pandemia em todo território nacional, que criam, por sua vez, ainda mais dificuldades para enfrentar uma crise sanitária de imensas implicações em todas as esferas da sociedade brasileira, e mundial.

Apenas para lançar mão de um pouco de matemática elementar, tomemos a cidade de Nova lorque, o grande centro financeiro do mundo, e sabidamente bem dotada de excelentes serviços de saúde. Para um população de cerca oito milhões e meio de pessoas, no momento que estas linhas são escritas, no dia 29 de março de 2020, 12.245 pessoas faleceram em decorrência da COVID-19², segundo dados oficiais. Tudo indica que só agora estão atravessando o pico epidêmico, com uma diminuição do número de mortos por dia. Estimativas realizadas em nosso grupo apontam para um total de 20 mil mortos ao final da atual fase. Caso a mesma taxa de mortalidade se repita no Brasil, onde as condições do sistema de saúde são certamente inferiores às de Nova lorque, teríamos cerca de 500 mil mortos, em todo o território nacional, nos próximos poucos meses. Uma estimativa muito mais conservadora e otimista aponta para cerca de 200 mil mortos causados pela COVID-19 no Brasil. O Brasil, também dados do dia 29 de abril, contabiliza cerca de 5.513 mortos $^{3}$, mas com um sistema que pode demorar até um mês para contabilizar todos os casos corretamente. A limitação do número de testes também é a principal fonte de grande subnotificação. Assim, é seguro afirmar que o país está ainda na fase inicial da sua epidemia, apesar de claros sinais de incompreensão desse fato central entre muitos tomadores de decisão. Cabe chamar a atenção para um erro frequente nas análises sobre a situação da pandemia no Brasil: o pico epidêmico, o ponto de maior número de pessoas infectadas por dia não é o mesmo em todos os lugares, e tampouco é o mesmo com ou sem medidas de mitigação, como o isolamento social.

Tudo isso aponta para a gravidade da situação. No entanto, autoridades públicas dos estados ainda com baixo número de óbitos vão a público informar que tudo está sob controle. Os governos de estados que já amargam grande número de óbitos se emocionam diante das câmaras e solicitam ajuda de qualquer espécie, pois seus sistemas de saúde já estão saturados. Não é de nenhuma forma exagero antecipar que os demais estados estejam, em breve, em situação similar, o que implicaria não apenas em número ainda maior de mortes por COVID-19, por falta de condições de atendimento aos casos mais graves, mas também em mortes por condições que seriam tratáveis em situação de normalidade, mas que também podem ser mortais no atual contexto, como uma simples apendicite.

Só existem, no presente momento, duas medidas capazes de evitar tal quadro: o isolamento social, pois diminui a velocidade de crescimento do número de casos por dia, diminuindo, por consequência, a demanda por leitos de hospital; e o aumento substancial da capacidade de atendimento pelo sistema de saúde. Esta última opção não se implementa da noite para o dia, requer não apenas espaço físico, mas também equipamentos e insumos, em grande parte importados, e contratação de pessoal, que deveriam ter sido planejados e implementados com a devida antecedência pelos respectivos gestores, e não quando a demanda já se faz urgente.

Para que informações de boa qualidade, necessariamente de teor complexo, sejam imediatamente

2 Dado disponível em: https://gisanddata.maps.arcgis.com/apps/opsdashboard/index.html\#/bda7594740fd40299423467b48e9ecf6 Consultado dia 30 de maio de 2020.

3 Dado disponível online em: https://gisanddata.maps.arcgis.com/apps/opsdashboard/index.html\#/bda7594740fd40299423467b48e9ecf6. Consultado dia 30 de maio de 2020. 
absorvidas por governantes e técnicos da administração pública, algumas medidas se fazem necessárias.

É comum, em vários países, constituir uma comissão de especialistas de diferentes áreas do conhecimento para avaliar a situação, interpretar os dados disponíveis, à luz do melhor conhecimento científico de nossa contemporaneidade, e fazer sugestões de ações e propor diferentes cenários e seus efeitos. É assim na França e nos Estados Unidos, onde os governos centrais valorizam, de forma muito diferente, o que a ciência Ihes provê. Os números mostram claramente quem tem razão. Enquanto na França a curva de casos já desacelera claramente, nos Estados Unidos nenhum sinal de arrefecimento pode ainda ser observado, ressalvadas as devidas diferenças por localidade, pois lá, com certas semelhanças com o Brasil, cada estado estabelece sua própria política de mitigação.

Outro ponto central é reconhecer que na ausência de uma vacina eficaz, o que não deve ocorrer antes de 2021, e a inoculação de uma ampla parte da população, que também requererá um tempo não desprezível, o isolamento social em diferentes graus é a única efetiva ferramenta de controle da pandemia. Países que acreditaram ser possível evitá-lo, como o Reino Unido, a Suécia, e o Japão, logo perceberam o erro, quando o número de casos de COVID-19 começou a sair de controle, e foram obrigados a implementar um isolamento social mais estrito. Este evidentemente implica um forte impacto na economia dos países, particularmente naqueles, como o Brasil, que têm um parcela significativa de sua população abaixo ou próxima da linha de pobreza. Sem forte apoio financeiro por parte do governo central, como é o caso em outros países, o isolamento social é uma sentença de falência de boa parte dos pequenos negócios, e mesmo de muitas grandes empresas, e desprovê boa parte da população de seus meios de sustento. A estratégia que se coloca é clara, incontornável e única: é necessário um programa abrangente de apoio financeiro, que garanta uma renda mínima a todas as pessoas colocadas em situação de vulnerabilidade econômica pelo isolamento social, assim como apoio real e efetivo, via linhas de crédito especiais, para as pequenas e médias empresas. As grandes empresas nacionais devem também ter um plano especificamente desenhado para elas. Mesmo que implique um maior nível de endividamento e aumento de impostos. A alternativa é deliberadamente escolher deixar que uma parcela significativa da população adoeça e morra. Além das óbvias questões éticas, isso também teria forte efeito duradouro na economia, e na sociedade como um todo. O painel de especialistas que o governo deveria estar ouvindo deve, portanto, contar com especialistas nas áreas financeira e econômica.

Temos ainda a questão dos dados para municiar as análises de forma mais precisa possível. O Brasil possui um sistema de vigilância sanitária público bem estruturado, que, apesar de suas muitas limitações, nos permite o acompanhamento contínuo de várias doenças transmissíveis (e também as não transmissíveis), como o sarampo e as diferentes arboviroses (principalmente dengue, zika e chikungunya). No caso da atual pandemia de COVID-19, e por conta de limitações variadas e por falta de capacidade de testagem, o sistema não consegue produzir dados que reflitam a realidade. Sabe-se que o número real de casos é ao menos uma ordem de grandeza maior do que divulgado oficialmente. Mesmo o número de óbitos é subestimado pois registros mostram que o número de mortes, em excesso à média histórica para o período, por síndrome respiratório aguda é maior do que o número oficial de mortes por COVID-194. Uma gestão de crises devidamente conduzida poderia ter evitado esse quadro. Se implementada agora, permite revertê-lo, ao menos parcialmente.

Finalmente, é imprescindível que os gestores públicos e todos os tomadores de decisão, incluindo aí os do setor privado, devem se conscientizar que não se trata de uma situação que se resolverá a curto prazo. Diferentes estudos (FLAXMAN et al., 2020; FERGUSON et al., 2020; ATKESON, 2020) apontam um período

\footnotetext{
4 Ver: MADEIRO, Carlos. Exames em mortos por síndrome respiratória fazem covid-19 explodir em PE. UOL, 18 de março de 2020. Disponível em: https://noticias.uol.com.br/saude/ultimas-noticias/redacao/2020/04/18/exames-em-mortos-por-sindrome-respiratoriafazem-covid-19-explodir-em-pe.htm; e MARINS, Carolina; MELLO, Igor; OLIVEIRA, Marcelo. Casos de covid-19 podem ser de 12 a 15 vezes o dado oficial, dizem estudos. UOL, 14 de março de 2020. Disponível em: https://noticias.uol.com.br/saude/ultimasnoticias/redacao/2020/04/14/pesquisas-subnotificacao-casos-confirmados-brasil.htm
} 
de vários anos até um controle mais efetivo da pandemia. É igualmente importante observar que ainda há muitos elementos desconhecidos sobre o SARS-CoV-2, e, à medida que o conhecimento científico avança, estratégias de mitigação devem ser adequadas. Mais uma razão para que o governo se informe corretamente com um painel de especialistas de ponta nas mais diferentes áreas, especialistas que hoje se encontram em Universidades e centros de pesquisa científica do nosso país. O papel do gestor público em compreender esse cenário, suas implicações, e coordenar as diferentes ações necessárias, se traduz em um número elevado de vidas. Para mais ou para menos.

Há dois anos, criamos, no Centro Internacional de Física da Matéria Condensada na Universidade de Brasília, o Núcleo de Altos Estudo Estratégicos para o Desenvolvimento, uma iniciativa multidisciplinar voltada ao estudo e proposição de políticas para problemas de alto interesse social.

Ao longo de 2019, desenvolvemos uma abordagem baseada em dados oficiais para descrever surtos de sarampo no Brasil e propor estratégias de controle por meio de campanhas de vacinação. Com o advento da atual pandemia, muitos de nossos pesquisadores se voltaram ao estudo dos seus efeitos, particularmente no Brasil, à construção de modelos de previsão para propor diferentes cenários de mitigação. Geramos, recentemente, um artigo submetido para publicação (FILHO et al., 2020) com prognóstico para a grande São Paulo, assim como uma série de relatórios e notas técnicas ${ }^{5}$ sobre nossa situação atual, que foram disseminados não apenas na comunidade científica, mas na imprensa e a gestores públicos. Esperamos que estes venham a considerar não apenas nossa contribuição, mas as de todos aqueles cientistas dedicados que procuram dar a melhor orientação possível para que, de forma organizada e humana, atravessemos essa longa e dolorosa crise.

Talvez a melhor forma de ilustrar o que uma falta de escuta ativa para os alertas da ciência é o comportamento dos mercados financeiros desde que o SARS-CoV-2 foi identificado em Wuhan, na China. As bolsas européias, americanas e do Brasil permaneceram otimistas e subindo até próximo do dia 19 de fevereiro deste ano, apesar de todos os alertas da Organização Mundial de Saúde e da comunidade científica. Apenas com os primeiros casos na Europa é que o "mercado eficaz", que precifica toda a informação disponível, decidiu internalizar o que já se sabia havia mais de um mês (WHO), causando fortes quedas na bolsas de valor ao redor do mundo. Mais recentemente, embalados por notícias de medicamentos milagrosos, entre eles a Cloroquina cuja eficácia foi rapidamente colocada em dúvida pela comunidade científica, e por perspectivas da criação de uma vacina que previna a COVID-19, os mercados financeiros vêm demonstrando uma gradual retomada. Infelizmente, apesar de muitas pesquisas promissoras em curso, nenhuma droga se mostrou até agora realmente eficaz, e não há como ter certeza que teremos uma vacina eficaz o suficiente no curto prazo, a saber o próximo ano. $O$ desenvolvimento e produção de uma vacina deve cumprir diferentes etapas demoradas, e é comum que demonstre resultados animadores inicialmente, falhe quando testada em humanos. Quando finalmente se tem uma vacina, há de se determinar sua eficácia, que nunca é de $100 \%$, e ser produzida em massa para a partir daí inocular uma grande parcela da população humana, o que levou décadas no casa da varíola. Em uma espécie de sebastianismo globalizado, remédios e vacinas prometem a grandes investidores assustados a volta do mundo pré-pandemia. Não são poucos os cientistas que reforçam o fato que o mundo pós-pandemia será diferente daquele que conhecemos até aqui,

É nossa mais profunda convicção que, sem o melhor conhecimento científico disponível, analisado por pessoas com larga e demonstrada experiência em suas respectivas áreas, o custo humano, social, e econômico será muito maior, e ressoará por anos a fio. O modo de vida que existia até 2019 não retornará tão cedo, se retornar. Análises amadoras e enviesadas não resultarão em nada diferente do que um desastre. O momento é de juntar especialistas em gestão pública, cientistas com os agentes públicos e

5 Alguns boletins e notas técnicas com evidências sobre a realidade da Pandemia Covid-19 no Brasil podem ser consultados em drive, neste link: https://drive.google.com/open?id=1NSavK7b0RGPLLz4FdSoCq1KzYELzqrVE. 
privados, para que estes possam tomar decisões embasadas em fatos científicos, e não em crenças ou desejos ${ }^{6}$.

\section{Referências}

ATKESON, Andrew. What Will Be the Economic Impact of COVID-19 in the US? Rough Estimates of Disease Scenarios. NBER Working Paper, n. 26867, p. 1-27, March 2020.

FERGUSON, Neil M.; LAYDON, Daniel; NEDJATI-GILANI, Gemma. et al. Impact of non-pharmaceutical interventions (NPIs) to reduce COVID-19 mortality and healthcare demand. Imperial College London, $p$. 1-20, 16 March 2020.

FILHO, Tarcisio M Rocha; SANTOS, Fabiana S. Ganem dos; GOMES, Victor B.; ROCHA, Thiago A. H.; CRODA, Julio H.R.; RAMALHO, Walter M.; ARAUJO, Wildo N. Expected impact of COVID-19 outbreak in a major metropolitan area in Brazil. MedRxiv, p. 1-11, March 2020.

FLAXMAN, Seth; MISHRA, Swapnil; GANDY, Axel et al. Estimating the number of infections and the impact of non-pharmaceutical interventions on COVID-19 in 11 European countries. Imperial College London, p. 1-35, 30 March 2020.

LUCIO, Magda de Lima; DANTAS, José M. M. Gestão, custos e governança pública: desenvolvimento nacional baseado em Public Intelligence. NAU - A Revista Eletrônica da Residência Social, v. 9, p. 92101, 2018.

; DAROIT, Doriana. Desenvolvimento, Ação Pública e Transversalidade dos Instrumentos de Gestão: um olhar sobre o Programa Bolsa Família. In: Lima Luciana, Rodrigues, Maria Isabel. (Orgs.). Campo de Públicas em Ação: coletânea em teoria e gestão de políticas públicas. Rio Grande do Sul: UFRGS, 2017, p. 292-314.

; BESSA, Luiz F M.; ABREU, A M. Sentidos e Significados de se Planejar Estrategicamente nas Organizações Públicas - Planejamento Estratégico Sociotécnico (PLANES): análise de uma experiência. NAU - A Revista Eletrônica da Residência Social, v. 5, p. 151-160, 2014.

MADEIRO, Carlos. Exames em mortos por síndrome respiratória fazem covid-19 explodir em PE. UOL, 18 de março de 2020. Disponível em: <https://noticias.uol.com.br/saude/ultimasnoticias/redacao/2020/04/18/exames-em-mortos-por-sindrome-respiratoria-fazem-covid-19-explodir-empe.htm>

MARINS, Carolina; MELLO, Igor; OLIVEIRA, Marcelo. Casos de covid-19 podem ser de 12 a 15 vezes o dado oficial, dizem estudos. UOL, 14 de março de 2020 . Disponível em: <https://noticias.uol.com.br/saude/ultimas-noticias/redacao/2020/04/14/pesquisas-subnotificacao-casosconfirmados-brasil.htm>

WHO - WORLD HEALTH ORGANIZATION. Pneumonia of Unknown Cause - China. Disease Outbreak News 2020. Disponível em: <https://www.who.int/csr/don/05-january-2020-pneumonia-of-unkown-causechina/en/>. Acesso em 26 de abril de 2020.

Novel Coronavirus (2019-NCoV) Situation Reports. Disponível em: $<$ https://www.who.int/emergencies/diseases/novel-coronavirus-2019/situation-reports $>$. Acesso em 26 de abril de 2020.

6 Agradeço a Clerismar Aparecido Longo, pesquisador do NAEED, pela cuidadosa revisão e auxílio na formatação do artigo. 